


\section{Bahía de Cádiz: lo singular de un territorio múltiple}

Luis F. Martínez Montiel, Dpto. de Escultura e Historia de las Artes Plásticas, U. de Sevilla
Más allá de su evidente configuración geográfica, la Bahía de Cádiz es un "estado mental". Perfectamente definible desde el exterior, es casi un constante y evanescente recuerdo diario en los que en ella habitan. Superando sus contradicciones, la bahía gaditana posee como un aire de familia a la que se discute y desafía desde dentro, pero a la que se defiende con ahínco y vehemencia frente al exterior. Para la mayoría de sus ciudadanos sus características físicas y climáticas la convierten en poco menos que un "paraiso en la tierra" y a ello se aferran, como se verá, sin mucho esfuerzo, para su disfrute. Sin embargo, la pertenencia a la comarca se define como un puzle, en el que cada una de sus piezas es diferente, autónoma

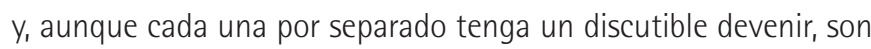
de gran potencia como colectivo. Cualquiera de las ciudades que la componen esgrimirá notables diferencias con el resto, sintiéndose difícilmente comparable. Quizás sea así, pero ante el espejo todas ellas tienen ese peculiar aire familiar del que se hablaba.

Pocas veces un término geográfico, como el de bahía, restringe tanto su significado como ocurre en el caso de la bahía gaditana. Su evidente implicación territorial es superada con creces por la amplitud de escenarios que subyacen bajo la denominación Bahía de Cádiz. Realidades que abarcan desde las más utópicas e idílicas visiones hasta las más duras certezas.

Su situación geográfica marcará desde los más remotos tiempos su trascendencia; sin embargo, la Bahía es más, mucho más que una privilegiada realidad geográfica donde se consolidaron los núcleos de Cádiz, San Fernando, Puerto Real, El Puerto de Santa María y Rota. Ciertamente su estratégica situación será determinante en todos sus aspectos, desde el demográfico hasta el económico, sin dejar a un lado el militar, uno de sus más poderosos argumentos hasta fechas muy recientes. Situada, como parada obligatoria, entre dos continentes, la bahía gaditana se verá influenciada por la liberalidad que poseen las zonas costeras y sobre todo fronterizas. África y Europa se conectan casi físicamente en ella, siendo además, no hay que olvidarlo, el eslabón básico de la conexión con América durante siglos. Todo ello marcará sus designios trascendentalmente, haciendo que en ella se asiente una importante masa de población. En ella se establecieron colonias fenicias y cartaginesas a las que más tarde se unirán los grandes flujos aportados por las grandes civilizaciones. Además, las posibilidades que le otorgaban sus peculiares caracteristicas físicas harán que rápidamente el comercio actúe como principal impulsor de su desarrollo poblacional.

El auge demográfico de la Bahía se producirá con el gran impulso económico que la repoblación cristiana potenciará. Históricamente la aprobación de un importante alfoz otorgado por Alfonso X será determinante como punto inicial de desarrollo. Unido esto a la obligatoria estrategia defensiva para hacer frente a las invasiones del norte de África, hará que se origine el establecimiento de una mayor población en el entorno para su defensa. El control de ese alfoz, aunque con algún que otro contratiempo, al estar gran parte de la Bahía implicada en las luchas fronterizas con el reino nazarí, seria fundamental en el desarrollo inicial; incluso este hecho hará posible el nacimiento de una de las ciudades que con el tiempo consolidará el potencial de la Bahía: Puerto Real, creada por los reyes católicos con el propósito de controlar los cada vez más continuos enfrentamientos.

Como ya se dijo, su trascendental situación geográfica sería desde sus orígenes motivo de interés de diferentes naciones, a las que en uno $u$ otro momento debieron incluso enfrentarse para salvaguardar la zona. Desde los inaugurales asaltos, llevados a cabo en el siglo XIV por los reyes portugueses y repetidos en el siglo XV, se van a producir toda una serie de ataques realizados desde Argel, la flota turca e incluso la británica, que finalmente acabarán consolidando una de las principales características de la zona: sus fortificaciones. Ya en esos momentos la Bahía empezará a tener un considerable peso geopolítico en las estrategias nacionales. De hecho, los continuos enfrentamientos con las tropas británicas en la Bahia harán que los mayores esfuerzos defensivos se concretaran en ella y que de esa forma se diera pie, por su mayor abandono, a que Gibraltar cayera en manos del Reino Unido. Por el contrario, esta conflictiva situación acabará modificando el territorio de la Bahía, pues la resistencia a estos asaltos produjo una serie de fortificaciones en todo el entorno que la convertirán en una de las zonas más y mejor fortificada de toda Europa. Esta transforma- 

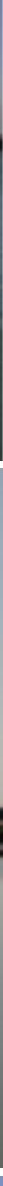

1. Vista de la Bahía desde San Fernando

2. Nuevo puente de La Pepa, en construcción

3. Restos de casa salinera en San Fernando

4. El puente Zuazo une San Fernando con la vecina localidad de Puerto Real

ción defensiva del frente marítimo motivará que, durante la Guerra de Independencia, las tropas francesas llevaran a cabo el asedio por tierra antes que por mar. Este último ataque produjo además el reforzamiento de toda la zona defensiva del entorno del puente Suazo, en la entonces Real Isla de León, fortaleciendo aun más el aspecto fortificado de gran parte de su territorio.

Pero si, como se ha descrito, la posición estratégica contribuirá a remodelar su fisonomía, no será menos importante su propia con- formación geográfica. Las amplias dimensiones de la Bahía, que incluso llegaba originalmente a terrenos jerezanos y chiclaneros, se iría recortando con los aportes de material del rio Guadalete, que a la postre iban a motivar la aparición de las marismas $y_{\text {, con }}$ ellas, la creación de una de las más importantes claves paisajísticas de la zona: las salinas. Es por tanto obligatorio reconocer, junto al componente físico de su territorio, la trascendencia de la actividad antrópica en su configuración. La trascendencia de la sal en un momento en que se consideraba la principal conservadora de 
Las salinas unen, a las

incuestionablemente necesarias

características geográficas, la acción

humana, que será la que acabe
creando ese paisaje salinero tan
vinculado a la imagen de la Bahía

alimentos potenciará esa actuación. En efecto, las salinas unen, a las incuestionablemente necesarias características geográficas, la acción humana, que será la que acabe creando ese paisaje salinero tan vinculado a la imagen de la Bahía. Desafortunadamente cada vez es menor el impacto salinero en la zona, sin embargo las roturaciones llevadas a cabo para sus actividades extractoras persisten, aunque aclimatadas a nuevos usos productivos, marcando gran parte del paisaje percibido de la Bahía.

Otro de los factores básicos en la configuración de la Bahía gaditana fue el descubrimiento de América. Desde los primeros momentos la zona se convertiria en uno de los principales núcleos desde los que se producia el arranque y atraque de naves que partían hacia el Nuevo Mundo. Aunque tradicionalmente se viene asociando que durante mucho tiempo el monopolio lo ejercía la ciudad de Sevilla, en la práctica, las ciudades de la Bahía asumirian un elevado nivel comercial, que incluso quedaría patente con la importante inmigración de comerciantes italianos y vizcaínos a la zona y que tanta significación tendrán con el tiempo en el propio carácter emprendedor y comercial de sus habitantes. Pero si, en los primeros momentos, su papel se puede decir que no fue principal, sí se verá reforzado cuando en 1717 se lleve a cabo el traslado de la Casa de Contratación a Cádiz. Puerto Real, El Puerto de Santa María, Rota e incluso la cercana Chiclana se verán favorecidas con ese aumento de población al que iba a acompañar la mayor importancia de la zona producida por el asentamiento o traslado a ella de otras grandes instituciones como ocurrirá poco después con la consolidación de la Armada en la zona de la Bahía. Es el momento, el siglo $X V I I I$, en el que ciudades como San Fernando, hasta entonces el "Aranjuez de los gaditanos", se convierte en una ciudad o cuando se crean la nueva población de San Carlos y el Arsenal de La Carraca, con el consiguiente aumento poblacional, vinculado al mundo militar, que tanto ha intervenido en la configuración territorial de la zona. Incluso en la actualidad, cuando el traslado de las dependencias militares ha potenciado el traspaso de unas poblaciones a otras de la Bahía, éste sigue siendo uno de los principales factores de modificación de su territorio. Si hasta casi fines del siglo XX la ciudad de San Fernando concentraba gran parte del Departamento de la Armada, establecido en ella en 1769, actualmente ese papel lo ha asumido Rota, por su mayor adecuación a las actuales necesidades. Sin embargo y pese a la paulatina pérdida de importancia en los núcleos originales, la implantación de la Armada fue tan potente que ha dejado marcado el territorio necesitándose una adecuación de sus usos a las nuevas circunstancias.
El inicio del siglo XIX no será benéfico para la zona pues la Guerra de la Independencia, la pérdida de las colonias americanas y el cese del monopolio del comercio con Indias iban a pronunciar el declive de la Bahía. Sin embargo, de nuevo su enclave geográfico será fundamental para la historia nacional. Su fácil aislamiento, no hay que olvidar el carácter insular de gran parte de la Bahía, permitirá que en ella se concentren las labores preparatorias de la primera Constitución Española. Este hecho acabará por conferir un carácter de especial liberalidad en la zona, que se convertirá en un argumento recurrente, especialmente potenciado en nuestros dias, cuando se celebra su segundo centenario. Pese a todo, la sustitución del comercio por los primeros intentos de industrialización de la zona la mantuvo casi en los mismos niveles. La creación de los astilleros en la Bahía y la conexión de sus ciudades a través del puente Carranza favorecería el tránsito y crecimiento de sus ciudades, aunque algunas, como es el caso de las ya citadas San Fernando o Puerto Real, iban a ir perdiendo importancia y convirtiéndose prácticamente en ciudades dormitorios de la capital.

En la actualidad, con la caída en importancia de su sector industrial, la Bahía se está volviendo a reinventar derivando su desarroIlo hacia el sector turístico, en el que la mayoria de sus ciudades tiene puesto su foco de crecimiento. Este desarrollo de cada uno de los núcleos habitacionales de la Bahía será por otra parte un factor determinante en la consolidación de su unidad territorial. Si hasta mediados del siglo XX cada municipio era claramente un enclave diferenciado, a partir de ese momento se fueron produciendo una serie de hechos, tanto a nivel geográfico como a nivel demográfico, que han ido favoreciendo claramente la integración de todos ellos en una mancomunidad con objetivos afines. Las vías de conexión sufrieron un importante avance y mejora con la apertura de diversos puentes -puente Carranza, desdoblamiento del puente Suazo y en un futuro el segundo puente sobre la Bahía-, y con una clara mejoría en sus vías de circulación que conectan las ciudades. Todo ello produjo un tránsito poblacional que ha enriquecido las relaciones y el sentido de pertenencia a una comarca. Comarca que, favorecida por la naturaleza, sólo necesita una buena gestión de sus recursos para poder continuar siendo un referente.

\section{Bibliografía}

BARRAGÁN MUÑOZ, J. M. (1995) Puerto, ciudad y espacio litoral en la bahía de Cádiz. Cádiz: Autoridad portuaria de la Bahía de Cádiz, 1995

BORDONS ALBA, C.; SALTO SÁNCHEZ DEL CORRAL, A. (2003) La Bahía de Cádiz: patrimonio natural y tecnológico de los andaluces. Sevilla: Consejería de Educación y Ciencia, 2003

FALCón MÁROUEZ, T. (1988) La Bahía de Cádiz en tiempos de Carlos III. Cádiz: Museo Histórico Municipal, 1988

LATOUR, A. DE (1986) La Bahía de Cádiz. Cádiz: Diputación Provincial, 1986 RAMOS SANTANA, A.; MALDONADO ROSSO, J. (1992) La Bahía de Cádiz en su unidad y diversidad a través de la Historia. Cádiz: Consejería de Cultura y Medio Ambiente, 1992

RUIZ NAVARRO, J. (1987) La Bahía de Cádiz: reconversión y reindustrialización. Cádiz: Diputación Provincial, 1987

SUÁREZ JAPÓN, J. M. (1989) La Casa Salinera de la Bahía de Cádiz. Cádiz: Fundación Machado, 1989 